\title{
Habitat Utilization of the Golden Takin During Later Au- tumn and Winter in Foping National Nature Reserve
}

\author{
SONG YANLING \\ Institute of Zoology Academia Sinica. Beijing 100080 \\ YU YUQUN \\ Zoological Institute of Shaanxi, Xian 710032 \\ GONG HUISHENG ZHANG SHANNING \\ Foping National Nature Reserve. Foping, shaanxi 723400 \\ (Received June 3, 1994, Revised July 25, 1994)
}

\section{ABSTRACT}

Total 275 quadrats with $400 \mathrm{~m}^{2}$ each in size were set up in the central area of Foping National Nature Reserve with elevation ranged between $1250 \sim 2400 \mathrm{~m}$ to collect data on habitat use of the Golden takins in 1991. Two checks were made on these quadrats in October 1991 and February 1992. Two huindred and seventy four quadrats were sampled in October 1991, 133 of the quadrats with tracks of the Golden takin. In February 1992, 245 quadrats were checked and only 102 were marked by takin tracks. The takins preferred both mixed coniferous and broadleaf deciduous forest and subalpine coniferous forest during later autumn and winter. The favored slope degree of habitat for the takin was about $30 \sim 60^{\circ}$ in the study sites. The elevations preferred by takin in mixed evergreen and deciduous broadleaf forest and coniferous forest varied from 1500 to $1900 \mathrm{~m}$ and in coniferous forest from 1900 to $2400 \mathrm{~m}$ in later autumn and winter. respectively. In the mixed coniferous and broadleaf deciduous forest, the preferred elevations changed from $1900 \sim 2400 \mathrm{~m}$ to 1500 $\sim 1900 \mathrm{~m}$ between October to February of next year. The slope aspect also influenced the habitat use by the golden takins.

Key words habitat utilization. golden takin. Foping National Nature Reserve

\section{INTRODUCTION}

The golden takins Budorcas taxicolor bedfordi are wholly confined to Qinling Mountain Areas of China, and they have been listed as Class I species to be protected by the Chinese Government. Date available on their habitat use is scant because they distribute in the mountainous areas where is hard to access. Efforts on research have been made in their ecological habits, food habits. and group size (Wu et al; 1966) since the $1960^{\prime}$ s. Between $1991 \sim 1992$, a research project on the habitat use was conducted for the purpose of habitat management in the Foping National Nature Reserve, Shaanxi, and the effort was made in the field to obtain information on the habitat selection of golden takins during later autumn and winter from October 1991 to February 1992.

THE STUDY AREA 
The study area was located in the central area of Foping National Nature Reserve which is geographically situated between $107^{\circ} 30^{\prime} \sim 109^{\circ} 0^{\prime}$ in longitude, and $32^{\circ} 30^{\prime} \sim 33^{\circ}$ $50^{\prime}$ in latitude, the local names of the study area are Sanguanmiao and Zhongzui. The area of the study site is about 7724 ha and is between $1350 \sim 2400 \mathrm{~m}$ in elevation. The vegetation in the study area shows a vertical zonation. A mixed evergreen and deciduous broadleaf forest can be found between $1100 \sim 2000 \mathrm{~m}$. Depending on the slopes, trees such as Castanopis, Fagus, Quercus, Castanea, Acer, Juglanus, Platycarya, and Salix can be found. A bamboo species, Bashania fargesii, together with other shrubs, forms the understory of this forest. Between $1400 \sim 2400 \mathrm{~m}$, a mixed coniferous and broadleaf deciduous forest predominates. Pinus, Abies, and Tsuga are the main speciés of conifers, and Quercus, Fraxinus, Betula, and Rhododendron are conspicuous among broadleaf trees and shrubs. Bamboo, Sinarundinaria nitida, also occurs in this type of forest. A subalpine coniferous forest occurs from 1800 to $2400 \mathrm{~m}$, predominated by Lar$i x$ and Abies. Butula, Rhododendron, and the bamboo, Fargesia spathacege form the understory within coniferous forest.

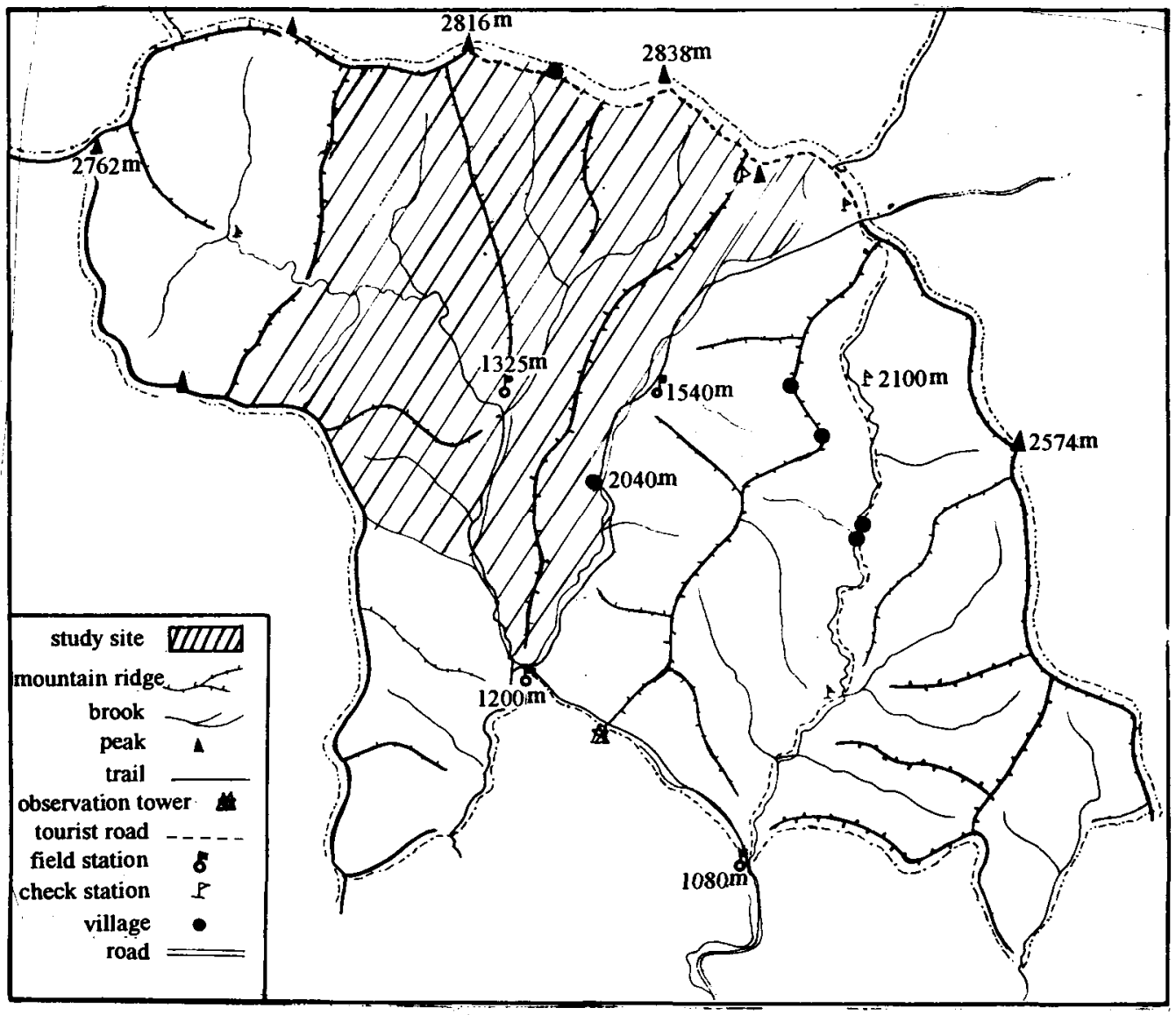

Fig. 1 Study area.

The human activity does not disturb the study area due to the lack of roads. Trails are available for people to travel on foot. The human activity influence that can be 
counted in the area was herb collection for traditional Chinese medicine by very few people during the autumn. Neither cultivation activities nor hunting were found in the study area.

The climate is temperate. The mean temperature in the National Nature Reserve is $13^{\circ} \mathrm{C}$. January is the coldest month (mean temperature $-2^{\circ} \mathrm{C}$ ) and July the warmest month (mean temperature $27^{\circ} \mathrm{C}$ ). The total precipitation is about $950 \sim 1200 \mathrm{~mm}$, most of which occurs from July to September. The first snow falls in the end of October and is melted soon after. The peak of the mountain is covered by snow all the winter and the snow will not melt until April of next year.

\section{STUDY METHODS}

Observation on the habitat use by golden takins was very difficult to make since they inhabit in forests within very rugged mountain areas. Therefore, takin tracks were selected as the index of habitat use. Total 275 quadrats with $400 \mathrm{~m}^{2}$ in size within the study area were set up during September 1991. Among them, 97 occurred in broadleaf forest, 125 and 53 in mixed coniferous and broadleafed deciduous forest and subalpine coniferous forest respectively. The quadrat was randomly arranged from the map. Each quadrat was separated with either $300 \mathrm{~m}$ interval in distance or $50 \mathrm{~m}$ difference in elevation or in both and marked with red flag with numbers. The elevation, slope degree, slope aspect, vegetation type were recorded. Two trips of check for the quadrats were conducted in October 1991 and February 1992 and the tracks, drops and any traces of takin in any quadrats were used as habitat use index of takin in the winter. No efforts were made to identify sex, age and herd size from tracks in the field work.

\section{RESULTS}

Information on quadrats with takin tracks during checks of October 1991 and February 1992 was shown in Table 1 and 2. Data were ranged by habitat types and elevation. Total 274 quadrats were sampled in October 1991, and 133 of them were found with takin tracks. The overall frequency of quadrats used by takin was about $48.5 \%$. the highest value occurred in coniferous forest, about $8.1 \%$ higher than overall frequency. The favorest elevation of the habitats used by takins could be found from these data. $1500 \sim 1900 \mathrm{~m}$ in broadleaf forest, $1900 \sim 2400 \mathrm{~m}$ in mixed coniferous and broadleaf deciduous forest, and coniferous forest.

Table 1 The use of habitat on elevation and forest types by golden takins in later autumn 1991.

\begin{tabular}{|c|c|c|c|c|c|c|c|c|c|c|c|c|}
\hline \multirow[t]{2}{*}{ Elevation } & \multicolumn{3}{|c|}{$\begin{array}{l}\text { Broad-leafed } \\
\text { forest }\end{array}$} & \multicolumn{3}{|c|}{$\begin{array}{l}\text { Mixed coniferous } \\
\text { and broadleafed } \\
\text { forest }\end{array}$} & \multicolumn{3}{|c|}{$\begin{array}{c}\text { Subalpine } \\
\text { coniferous } \\
\text { forest }\end{array}$} & \multicolumn{3}{|c|}{ Overall } \\
\hline & A & B & $\mathrm{C}$ & A & B & C & A & B & $\mathrm{C}$ & A & B & C \\
\hline Below $1500 \mathrm{~m}$ & 35 & 6 & 0.172 & 8 & 4 & 0.500 & - & - & - & 43 & 10 & 0.233 \\
\hline $1501 \sim 1900 \mathrm{~m}$ & 59 & 29 & 0.492 & 86 & 43 & 0.500 & 13 & 7 & 0.539 & 158 & 79 & 0.500 \\
\hline $1901 \sim 2400 \mathrm{~m}$ & 3 & 1 & 0.333 & 30 & 20 & 0.667 & 40 & 23 & 0.575 & 73 & 44 & 0.603 \\
\hline Total & 97 & 36 & 0.371 & 124 & 67 & 0.540 & 53 & 30 & 0.566 & 274 & 133 & 0.485 \\
\hline
\end{tabular}

A: No. of quadrats B: Quadrats with tracks C: Frequency 
Table 2 The use of habitat on elevation and forest types by golden takins in winter of $1991 \sim 1992$.

\begin{tabular}{|c|c|c|c|c|c|c|c|c|c|c|c|c|}
\hline \multirow[t]{2}{*}{ Elevation } & \multicolumn{3}{|c|}{$\begin{array}{c}\text { Broad leafed } \\
\text { forest }\end{array}$} & \multicolumn{3}{|c|}{$\begin{array}{c}\text { Mixed coniferous } \\
\text { and broadleafed } \\
\text { forest }\end{array}$} & \multicolumn{3}{|c|}{$\begin{array}{c}\text { Alpine } \\
\text { coniferous } \\
\text { forest }\end{array}$} & \multicolumn{3}{|c|}{ Overall } \\
\hline & A & $\mathrm{B}$ & $\mathrm{C}$ & $\mathrm{A}$ & B & $\mathrm{C}$ & A & B & C & A & B & $\mathrm{C}$ \\
\hline Below $1500 \mathrm{~m}$ & 29 & 6 & 0.207 & 9 & 2 & 0.222 & - & - & - & 38 & 8 & 0.211 \\
\hline $1501 \sim 1900 \mathrm{~m}$ & 55 & 25 & 0.455 & 75 & 32 & 0.427 & 13 & 5 & 0.385 & 143 & 62 & 0.434 \\
\hline $1901 \sim 2400 \mathrm{~m}$ & 3 & 1 & 0.333 & 22 & 8 & 0.364 & 39 & 23 & 0.590 & 64 & 32 & 0.500 \\
\hline Total & 87 & 32 & 0.368 & 106 & 42 & 0.396 & 52 & 28 & 0.528 & 245 & $\cdot 102$ & 0.416 \\
\hline
\end{tabular}

A: No. of quadrats B: Quadrats with tracks C: Frequency

Two hundred and fourty five quadrats were relocated in the check of February 1992. Totally, 102 quadrats were marked by takin tracks. The frequency value of quadrat with tracks to total quadrats was $41.6 \%$ in overall which was little less than that in October 1991. The favorest elevation of takins in this check was $1500 \sim 1900 \mathrm{~m}$ in the broadleaf forest, and $1900 \sim 2400 \mathrm{~m}$ in coniferous forest the same as in the October, 1991. Difference in elevation between autumn and winter was found in mixed coniferous and deciduous broadleaf forest, the habitat between $1500 \sim 1900 \mathrm{~m}$ in mixed coniferous and broadleaf forest was preferred by the takins during winter.

The slope degree also influenced the habitat use of the takin (Table 3), they preferred to use the habitats located between $31 \sim 60^{\circ}$ degrees of slope in later autumn, however in winter they were found to use the hatitats with gentle slopes. The quadrats with steep slopes were avoided by the takins in our study area.

Table 3 Slope degrees of the habitats used by golden takins.

\begin{tabular}{c|ccc|ccc|ccc}
\hline \multirow{2}{*}{ Degree of slope } & \multicolumn{3}{|c|}{ Fall } & \multicolumn{3}{c|}{ Winter } & \multicolumn{3}{c}{ Overall } \\
\cline { 2 - 11 } & $\mathrm{A}$ & $\mathrm{B}$ & $\mathrm{C}$ & $\mathrm{A}$ & $\mathrm{B}$ & $\mathrm{C}$ & $\mathrm{A}$ & $\mathrm{B}$ & $\mathrm{C}$ \\
\hline Below $30^{\circ}$ & 99 & 41 & 0.414 & 97 & 41 & 0.423 & 196 & 82 & 0.418 \\
$31 \sim 60^{\circ}$ & 152 & 84 & 0.553 & 140 & 49 & 0.350 & 292 & 133 & 0.455 \\
$60^{\circ}$ above & 8 & 2 & 0.250 & 8 & 2 & 0.250 & 16 & 4 & 0.250 \\
\hline Total & 259 & 127 & 0.490 & 245 & 92 & 0.376 & 504 & 219 & 0.435 \\
\hline
\end{tabular}

A: No. of quadrats B: Quadrats with tracks C: Frequency

\section{DISCUSSION}

The golden takin is a species distributing in subalpine forests between $1500 \sim 4500 \mathrm{~m}$ in elevation (Allen 1940; Wu et al 1986a). They inhabit in the mixed coniferous and broadleaf deciduous forest and subalpine coniferous forest (Wu et al 1990). In our study area, the golden takins were first found to use broadleaf deciduous forest that occured as low as $1200 \mathrm{~m}$ in altitude in both autumn and winter (Table 1,2), although they used the mixed coniferous and broadleaf deciduous forest and subalpine coniferous forest more often. In later autumn, the golden takin in our study area preferred both of the mixed coniferous and deciduous broadleaf forest, and coniferous forest. The frequencies of quadrats used by the takins during October check in the mixed coniferous and broadleaf deciduous forest, and coniferous forest were higher than average. 
Traclitionally, people believe that the takin.inhabits on the mixed coniferous and deciduous broadleaf forest, and subalpine coniferous forest, and prefers travelling along slopes which is as steep as $70^{\circ}$ degrees. Our observation proved that generally the takin travelled along the mountain ridges with gentle slopes within their habitat. The takin had to make movement in a steep slope only in the case that they tried to escape from any danger. The quadrats with steep slopes were avoided by the takin, no matter what kind of habitats they were located in our study site although they could travel in steep slope without any problem.

In order to determine if the takins had specific preference for any aspects of slope, we ranged the data by slope aspect for all the habitat types. The golden takin liked to use habitats located in the east, southeast, southwest and northwest aspects of the slope in our overall calculation (Table 4) during later autumn. But when surveying each habitat type, we found that the takins preferred east slope in broadleaf forest, southeast, west, southwest, northwest slopes in mixed coniferous and broadleaf deciduous forest, and east, southeast, southwest and northwest slopes in coniferous forest. The takin did not use habitats located in south slope more often in autumn.

Table 4 The use of habitat on slope aspects and forest types in later autumn 1991.

\begin{tabular}{|c|c|c|c|c|c|c|c|c|c|c|c|c|}
\hline \multirow[t]{2}{*}{ Slope asfect } & \multicolumn{3}{|c|}{$\begin{array}{l}\text { Broad leafed } \\
\text { forest }\end{array}$} & \multicolumn{3}{|c|}{$\begin{array}{c}\text { Mixed coniferous } \\
\text { and broadleafed } \\
\text { forest }\end{array}$} & \multicolumn{3}{|c|}{$\begin{array}{l}\text { Subalpine } \\
\text { coniferous } \\
\text { forest }\end{array}$} & \multicolumn{3}{|c|}{ Overall } \\
\hline & A & B & $\mathrm{C}$ & A & $\mathrm{B}$ & $\mathrm{C}$ & A & $\mathrm{B}$ & $\mathrm{C}$ & A & B & $\mathrm{C}$ \\
\hline East & 20 & 10 & 0.500 & 13 & 6 & 0.461 & 5 & 4 & 0.800 & 38 & 20 & 0.526 \\
\hline Southeast & 8 & 1 & 0.125 & 22 & 15 & 0.682 & 10 & 3 & 0.300 & 40 & 19 & 0.463 \\
\hline Northeast & 5 & 1 & 0.200 & 15 & 5 & 0.333 & 3 & 2 & 0.667 & 23 & 8 & 0.348 \\
\hline West & 12 & 0 & 0 & 11 & 7 & 0.636 & 1 & 1 & 1.000 & 24 & 8 & 0.333 \\
\hline Southwest & 3 & 1 & 0.333 & 35 & 23 & 0.657 & 13 & 3 & 0.231 & 51 & 27 & 0.529 \\
\hline Northwest & - & - & - & 9 & 8 & 0.889 & 3 & 2 & 0.667 & 12 & 10 & 0.833 \\
\hline Sourh & 10 & 2 & 0.200 & 13 & 7 & 0.538 & 6 & 2 & 0.333 & 29 & 11 & 0.379 \\
\hline Nor:h & 1 & 0 & 0 & 12 & 3 & 0.250 & 3 & 0 & 0 & 16 & 3 & 0.188 \\
\hline Total & 59 & 15 & 0.254 & 130 & 74 & 0.569 & 44 & 17 & 0.386 & 233 & 106 & 0.455 \\
\hline
\end{tabular}

A: No. of cuadrats B: Quadrats with tracks C: Frequency

Like in the autumn, the takins used sites in mixed coniferous and broadleaf deciduous forest and coniferous forest with higher frequencies than in mixed evergreen and deciduous tiroadleaf forest during winter (Table 5). The takins used east, southeast and northwest slopes more of ten than any other slope aspects in overall during winter. For each habitat type the takins preferred east, southeast, west slopes in mixed evergreen and deciduous broadleaf forest, southeast, northeast, west and northwest slopes in mixed coniferous and broadleaf deciduous forest, and east, southeast and northwest slopes in coniferous forest. The sites in south slope of mountainous area were not preferrred even in the winter. The reason is still unknown.

The vertical movement of the takins was found from season to season in the mixed coniferous and deciduous broadleaf forest, but was not found in evergreen and deciduous broadleaf forest, and subalpine coniferous forest. This result did not agree with observations made by $\mathrm{Wu}$ et al (1986). The favored elevation by the takins in winter was ob- 
viously lower than that in later autumn in the mixed coniferous and broadleaf deciduous Table 5 The use of habitat on slope aspects and forest types by golden takins in winter of 1991 1992.

\begin{tabular}{|c|c|c|c|c|c|c|c|c|c|c|c|c|}
\hline \multirow[t]{2}{*}{ Slope aspect } & \multicolumn{3}{|c|}{$\begin{array}{l}\text { Broad leafed } \\
\text { forest }\end{array}$} & \multicolumn{3}{|c|}{$\begin{array}{c}\text { Mixed coniferous } \\
\text { and broadleafed } \\
\text { forest }\end{array}$} & \multicolumn{3}{|c|}{$\begin{array}{c}\text { Subalpine } \\
\text { coniferous } \\
\text { forest }\end{array}$} & \multicolumn{3}{|c|}{ Overall } \\
\hline & A & B & C & A & B & $\mathrm{C}$ & $\mathrm{A}$ & $B^{*}$ & $\mathrm{C}$ & A & B & C \\
\hline East & 22 & 17 & 0.773 & 9 & 2 & 0.222 & 4 & 3 & 0.750 & 35 & 22 & 0.629 \\
\hline Southeast & 6 & 5 & 0.833 & 16 & 8 & 0.500 & 11 & 5 & 0.455 & 33 & 18 & 0.546 \\
\hline Northeast & 6 & 2 & 0.333 & 17 & 8 & 0.471 & 4 & 2 & 0.500 & 27 & 12 & 0.444 \\
\hline West & 15 & 1 & 0.067 & 4 & 2 & 0.500 & 2 & 1 & 0.500 & 21 & 4 & 0.191 \\
\hline Southwest & 7 & 2 & 0.286 & 16 & 5 & 0.313 & 12 & 7 & 0.583 & 35 & 14 & 0.400 \\
\hline Northwest & 2 & 0 & 0 & 7 & 4 & 0.571 & 4 & 3 & 0.750 & 11 & 9 & 0.818 \\
\hline South & 16 & 7 & 0.438 & 10 & 4 & 0.400 & 6 & 2 & 0.333 & 32 & 13 & 0.406 \\
\hline North & 9 & 2 & 0.222 & 10 & 4 & 0.400 & 3 & 0 & 0 & 22 & 6 & 0.273 \\
\hline Total & 81 & 38 & 0.469 & 89 & 37 & 0.416 & 46 & 23 & 0.500 & 216 & 98 & 0.454 \\
\hline
\end{tabular}

A: No. of quadrats B: Quadrats with tracks C: Frequency

forest, but in evergreen and deciduous broadleaf forest and coniferous forest the elevation preferred by takins did not change significantly between later autumn and winter. It was understandable that the temperature did not change very much in the mixed evergreen and deciduous broadleaf forest between autumn and winter, but the temperature would vary greatly in the subalpine coniferous forest from season to season since it occured in elevation in the mountainous areas. The reason why the golden takins did not make a vertical movement between autumn and winter in coniferous forest could not be addressed by this field work.

\section{ACKNOWLEDGEMENTS}

Appreciation should specially be given to the heads, Zhang Jian and Yang Shuiquan, in Foping National Nature Reserve. They encouraged this field work and managed to support this research in finance. Also, we are appreciative for the people who worked in the sanquanmiao and Daguping field observation stations. They provided us the necessity of living and accommodations when we worked in the field.

\section{REFERENCES}

Allen G M, 1940. The mammals of China and Mongolia. Amer. Mus. Nat. Hist. , 1:1249 1258

Wu Jiayan. Han Yiping, Yong Yange, Zhao Junwu, 1986. A preliminary study on food habits and characters of population of the Chinese takin. La Animal Mondo, $3(2): 1 \sim 15$ (in Chinese)

Wu Jiayan, 1986. The systematic and distribution of the takin. Zoological Research, 7 (2): 167 175 (in Chinese)

Wu Jiayan et al., 1990. The Chinese takin. China Forestry Publication House, 192 (in Chinese) 